$\operatorname{cocos}(2004), 16,22-36$

Printed in Sri Lanka

\title{
DEVELOPMENT OF A METHOD FOR MASS REARING OF NEOSEIULUS BARAKI, A MITE PREDATORY ON THE COCONUT MITE, ACERIA GUERRERONIS
}

\author{
L C P Fernando, N S Aratchige, S L M L Kumari, \\ P A L D Appuhamy and D C L Hapuarachchi
}

Coconut Research Institute, Lunuwila, Sri Lanka

\begin{abstract}
Studies in Sri Lanka revealed that Neoseiulus baraki Athias-Henriot (Acari: Phytoseiidae) (previously referred to as Neoseiulus aff. paspalivorus) is a prospective biological control agent of the coconut mite, Aceria guerreronis Keifer (Acari: Eriophyidae). Mass rearing of the predatory mite, N. baraki was proposed to augment the field population. Laboratory studies were conducted to determine an alternative prey for $N$. baraki, a food source for rearing of the alternative prey and a suitable arena for rearing of the predatory mite and the alternative prey. $N$. baraki developed and multiplied satisfactorily on the storage mite, Tyrophagus putrescentiae Shrank (Acari: Ascidae). The predatory mite when fed on $T$. putrescentiae developed from egg to adult in $11.1 \pm 0.1$ days and deposited $26.4 \pm 2.2$ eggs during a life-time of $70.0 \pm 1.8$ days. $T$. putrescentiae multiplied equally well on pollen of Typha sp. and rice bran. The fecundity of $T$. putrescentiae was $163.5 \pm 23.4$ eggs on Typha pollen and $143.7 \pm 9.7$ eggs on rice bran. But the daily oviposition rate was higher on rice bran. The predatory mite and its alternative prey could be bred in the same arena, which is a modification of the basic arena described by McMurtry \& Scriven (1965). A closed arena without a water barrier was the most suitable rearing system to obtain a higher number of predatory mites. In this arena a single female predatory mite gave rise to 24 motile stages and eggs in three weeks. Advantages and disadvantages of the rearing method are discussed.
\end{abstract}

\section{INTRODUCTION}

The coconut mite, Aceria guerreronis Keifer (Acari: Eriophyidae) is one of the most intractable pests of coconut in the world. Since the first report of it in 1965 from Mexico it has spread in to many countries in the Americas and Africa (Hall and Espinosa, 1981; Mariau, 1977; Mariau and Julia, 1970; Zuluaga and Sanchez, 1971) and to India and Sri Lanka in 1997 (Fernando, 1998; Fernando et al. 2002; Sathiamma et al. 1998). No sustainable method has yet been developed to manage the pest successfully. The only effective way of managing the pest has been the use of pesticides. Although 
pesticides suppress the pest populations, they have to be applied repeatedly at short intervals to maintain the pest population below economic damage level. Such a method is uneconomical, impractical and moreover environmentally undesirable as a long-term measure. Therefore, chemical methods are useful only as a short-term control measure of coconut mite. Biological control methods such as the use of entomopathogenic fungus, Hirsutella thompsonii Fisher has shown some promise, but effective control methods using this fungus have not been developed yet (Cabrera, 1995; Lampedro and Rosas, 1989; Rabindra and Kumar, 2003).

Several predatory mites of $A$. guerreronis have been recorded from many coconut-growing countries of the world (see Moraes and Zacarias, 2002). But, their impact on the coconut mite and potential as biological control agents has not been explored. It has been suggested that Neoseiulus spp. (Phytoseiidae) have potential as prospective candidates because they do not prefer too much light and their bodies are flat enabling them to creep underneath the tepals of coconuts (Moraes and Zacarias, 2002). In Sri Lanka, Neoseiulus baraki was found underneath the bracts of nuts infested with coconut mite. Both laboratory and field studies strongly suggest that this predatory mite is a promising candidate for the biological control of coconut mite. This species previously referred as $N$. aff. paspalivorus is probably Neoseiulus baraki Athias-Henriot (Moraes, pers. comm.). Hence, it will be referred to as $N$. baraki, hereafter. Field studies revealed that the density of $N$. baraki has a strong temporal relationship with the density coconut mite (Fernando et al. 2003). In general, the distribution and density. of the predatory mites on nuts have increased over time (Fernando and Aratchige, 2003). However, predatory mites were not found on all the nuts of a palm although they were present in all the palms in varying numbers (Fernando et al. 2003). Also, field observations indicated that the density of predatory mites found in nature are often not sufficient to effectively reduce the coconut mite density and damage. Therefore, augmenting the field population by releasing laboratory-bred predators need to be attempted to reduce and maintain low levels of coconut mite. Such a programme will require mass-breeding of the predatory mite in the laboratory. No attempts have been made either to study the biology or the method of rearing the predatory mite as it has not been considered as an important biological control agent.

The predatory mite, $N$. baraki could be easily reared in the laboratory on $A$. guerreronis bred on embryo-cultured seedlings (de Silva, pers. comm.). But it is difficult to use this method due to the high cost and labouir involved in the production of embryo-cultured seedlings. Therefore, it was necessary to find an alternate food source to rear the predatory mite. Previous studies with different food sources such as pollen from different plants, other eriophyoid mites and artificial diets did not yield successful results (Aratchige et al., 2001). 
The paper presents the studies conducted to determine a suitable prey for the laboratory rearing of the predatory mite, a suitable food source for the prey mite and identifying a rearing unit to mass breed $N$. baraki.

\section{MATERIALS AND METHODS}

\section{Rearing arenas}

The basic rearing unit (arena) described by McMurtry and Scriven (1965) was modified and used in experiments to determine a suitable food source for $N$. baraki and its prey. The arena consisted of a $5 \mathrm{~cm} \times 5 \mathrm{~cm}$ black paper waxed by dipping in hot bees wax and laid on $2.5 \mathrm{~cm}$ thick foam of the same size. The foam was placed in a $9 \mathrm{~cm}$ diameter petri dish filled with water up to $2 \mathrm{~cm}$ height of the foam. Tissue paper strips of $2.5 \mathrm{~cm}$ wide with one edge suspended in water were stretched around the periphery of the wax paper to discourage escape and provide drinking water. In each arena two coverslips were laid on strands of cotton wool as oviposition sites and shelter for mites. Eight arenas were arranged in a plastic tray $(45 \mathrm{~cm} \times 35$ $\mathrm{cm}$ ) having a thin layer of water and covered with an inverted tray of the same size. Water levels of the arenas were maintained by adding water regularly.

\section{Mother cultures}

\section{N. baraki}

N. baraki were collected from coconut mite infested nuts collected from Puttalum District (North western Province). N. baraki was reared in the arenas described above. About 5 females and 1-2 males were introduced in to each arena and were supplied with coconut mites collected from infested nuts, every 2 days. The culture was maintained by transferring excess predators to new arenas from time to time. The arenas were kept in an incubator at a temperature of $27 \pm 0.5^{\circ} \mathrm{C}$ and $85-95 \% \mathrm{RH}$.

\section{Tetranychus cinnabarinus}

T. cinnabarinus Boisduval (Acari: Tetranychidae) was collected from cassava plants [Manihot esculenta (Crantz)] grown around the Coconut Research Institute at Lunuwila (NWP). Polyethylene tubes (1 $\mathrm{m}$ long and 15 $\mathrm{cm}$ wide) were filled with coir dust and 3-4 stem cuttings of cassava were planted in each tube placed horizontally on benches in a screen house. When 3-4 leaves were produced, field collected $T$. cinnabarinus were placed on cassava leaves for multiplication. 


\section{Tyrophagus putriscentiae}

The storage mite, $T$. putriscentiae Shrank (Acari: Ascidae) found in small numbers on coconuts infested with coconut mite were collected and reared on arenas described above. Pollen of the water plant Typha sp. was provided as food. Pollen from Typha flowers were removed by brushing the flowers on to a paper. Pollen were dried in an oven at $40^{\circ} \mathrm{C}$ for 2 hours and stored in airtight glass vials in a refrigerator at $5^{\circ} \mathrm{C}$. Pollen was lightly sprinkled on to the rearing arena by tapping a fine brush dipped in pollen. The culture was maintained in an incubator at $27 \pm 0.5^{\circ} \mathrm{C}$ and $85-95 \% \mathrm{RH}$.

\section{Determination of a suitable food source for rearing $\mathbf{N}$. baraki}

\section{Development on different food sources}

Four food sources were tested to determine their suitability for the development of $N$. baraki. The food sources were $A$. guerreronis, $T$. cinnabarinus, coconut pollen, a combination of $T$. cinnabarinus and Typha pollen and $T$. cinnabarinus and coconut pollen. $A$. guerreronis were collected from the infested nuts and eggs of $T$. cinnabarinus were collected from infested plants grown in the screen house. Typha pollen was obtained from flowers collected from the field. Pollen was processed and stored as given above. Forty arenas were prepared and a single egg of $N$. baraki was placed on each arena. Each of ten arenas was provided with one of four types of food types after the eggs hatched. Eight arenas were arranged randomly in one plastic tray and incubated at $27 \pm 0.5^{\circ} \mathrm{C}$ and $85-95 \% \mathrm{RH}$. Arenas were examined daily and the developmental stage of the predatory mite was recorded until adulthood. Arenas were cleaned and supplied with abundance of fresh food material every two days.

\section{Fecundity on different food sources}

$N$. baraki was reared on $A$. guerreronis, $T$. cinnabarinus, coconut pollen, $T$. cinnabarinus and Typha pollen, $T$. cinnabarinus and coconut pollen separately. At the deutonymph stage ten females of $N$. baraki that developed on each of the food source removed and were placed on individual arenas. Each female was confined with a single male for 2 days. They were allowed to feed on their respective food sources on which they developed. Eight arenas were randomly placed on each tray and incubated at $27 \pm 0.5{ }^{\circ} \mathrm{C}$ and $85-95 \% \mathrm{RH}$. The arenas were observed daily and the date on which each deutonymph developed into an adult and laid the first egg was recorded. The number of ovipositions was recorded every two days until their death. The food source was renewed regularly. 


\section{Development and fecundity on T. putrescentiae}

Preliminary observations revealed that $N$. baraki feeds on eggs and newly hatched nymphs and therefore could be reared on $T$. putrescentiae. Therefore, a study was conducted to determine the durations of development and the total fecundity of $N$. baraki on the host. Ten females and 10 males of $T$. putrescentiae were introduced to each of 20 arenas and provided with Typha pollen as food. The arenas were kept for 7 days in the incubator at $27 \pm 0.5^{\circ} \mathrm{C}$ and $80-90 \% \mathrm{RH}$. On the eighth day one egg of $\mathrm{N}$. baraki was introduced to each arena. The arenas were examined daily and the stage of development was recorded. At the deutonymph stage arenas with females were provided with a male and the number of ovipositions was recorded daily until their death. Typha pollen was provided regularly as food for $T$. putrescentiae. Eggs of $T$. putrescentiae were introduced to the arenas if the numbers of eggs present on the arenas were not sufficient. Eight arenas were randomly placed on each tray and incubated at the same conditions.

\section{Determination of development and fecundity of $T$. putrescentiae on Typha pollen and rice bran}

Rate of development and total fecundity of T. putrescentiae on Typha pollen and rice bran were studied to determine the food material most suitable for rearing $T$. putrescentiae. Thirty- eight arenas were prepared and a single egg of $T$. putrescentiae was placed on each arena. Typha pollen was supplied as food. The arenas were incubated at a temperature of $27 \pm 0.5^{\circ} \mathrm{C}$ and $85-95 \% \mathrm{RH}$ and checked daily until up to the adult stage. At this stage arenas with males were discarded and a single male was introduced to each arena with a female. The arenas were observed daily and the number of ovipositions was recorded until death of the females. Eggs laid were recorded and removed after each observation. Fresh pollen was supplied every two days.

Suitability of rice bran for rearing of $T$. putrescentiae was studied separately. Forty-eight arenas were used in the study and about $1 / 4$ teaspoon of rice bran was placed in each arena instead of pollen. The procedure used in the previous study was followed.

\section{Determination of a suitable arena for mass rearing}

The arena that was used in the earlier studies was not sufficient to breed large numbers of the predatory mite. Also, the mites tend to escape from the arena in spite of the water barrier. Three different types of arenas were developed by modifying the basic arena and were evaluated to determine their suitability. The 3 arenas were a closed arena with a water barrier, a closed arena without a water barrier and an open arena with a water barrier. 
The arenas with the water barrier comprised of a black wax paper $(9.5 \mathrm{~cm} \times$ $5.5 \mathrm{~cm}$ ) placed on a piece of foam of similar size having a height of $2.5 \mathrm{~cm}$. The arena was placed inside a plastic box $(14 \mathrm{~cm} \times 9 \mathrm{~cm} \times 4.5 \mathrm{~cm})$. The box was filled with water up to the level of $0.5 \mathrm{~cm}$ below the wax paper. Strips of tissue paper of $4 \mathrm{~cm}$ wide with one edge suspended in water were stretched along the periphery of the wax paper. In each arena two coverslips were placed on strands of cotton wool. The arenas without the water barrier were similar except that the wax paper and the foam was bigger $(13 \mathrm{~cm} \times 8 \mathrm{~cm} \times$ $2.5 \mathrm{~cm}$ ). The edges of the strips of tissue paper were folded upwards to line the sides of the box. The foam was thoroughly wetted to keep the tissue moist. For the closed arena a hole of $5 \mathrm{~cm} \times 9 \mathrm{~cm}$ was cut on the lid of the box and glued with parachute cloth for aeration and to prevent escape of mites. The open arena did not have a lid.

Five arenas were used for each type and 100, T. putriscentiae were introduced in to each. Typha pollen was provided as food. The arenas were kept in an incubator at $27 \pm 0.5^{\circ} \mathrm{C}$ and $85-95 \% \mathrm{RH}$ for 7 days for the establishment of $T$. putrescentiae. Two female deutonymphs and one male of the predatory mite were introduced in to each arena and continued to maintain in the same conditions. Arenas were checked regularly and food and water were provided when necessary. The number of predatory mites in each arena was counted every 7 days up to 3 weeks.

\section{Mass rearing of $\mathbf{N}$. baraki}

Breeding of the predatory mite was initiated in an air-conditioned insectary room at $27 \pm 2^{\circ} \mathrm{C}$. $T$. putrescentiae was reared on rice bran in a closed arena without a water barrier. Six such arenas were placed in a plastic tray $(45 \mathrm{~cm}$ $\times 35 \mathrm{~cm}$ ) and covered with an inverted plastic tray of same size to maintain $80-90 \% \mathrm{RH}$. The foam and the tissues were moistened weekly. Two females and one male $N$. baraki were introduced in to each arena. From them, 17 arenas were randomly selected and the number of mobile predatory mites and their eggs were counted weekly up to 3 weeks after introduction.

\section{RESULTS}

\section{Determination of a suitable food source for rearing of N. baraki}

\section{Development on different food sources}

Duration of development of the predatory mite on different food sources were compared using Kruskal-Wallis Non-parametric Test. The predatory mite developed to adulthood on all the food sources. Duration of development of larva and protonymph were not significantly different but 
duration of deutonymph and egg to adult were significantly different among when fed on the 4 food sources (Table 1). The shortest duration of development of 5.6 days was obtained when fed on $A$. guerreronis.

Table 1: Mean duration of development stages of $N$. baraki on different food sources

\begin{tabular}{lllll}
\hline Food source & \multicolumn{4}{c}{$\begin{array}{c}\text { Duration of developmental stage } \\
\text { Mean } \pm \text { S.E. (days) }\end{array}$} \\
\cline { 2 - 5 } & Larva & Protonymph & Deutonymph & Egg - adult \\
\hline A. guerreronis & $1.4 \pm 0.3$ & $2.0 \pm 0.3$ & $2.2 \pm 0.4$ & $5.6 \pm 0.4$ \\
T. cinnabarinus & $2.3 \pm 0.3$ & $3.2 \pm 0.4$ & $2.7 \pm 0.4$ & $8.2 \pm 0.6$ \\
$\begin{array}{l}\text { T. cinnabarinus \& } \\
\text { Typha pollen }\end{array}$ & $2.0 \pm 0.2$ & $2.9 \pm 0.4$ & $2.5 \pm 0.3$ & $7.4 \pm 0.5$ \\
$\begin{array}{l}\text { T. cinnabarinus \& } \\
\text { coconut pollen }\end{array}$ & $1.7 \pm 0.1$ & $2.2 \pm 0.4$ & $2.4 \pm 0.4$ & $6.3 \pm 0.7$ \\
Coconut pollen & $1.9 \pm 0.2$ & $2.6 \pm 0.4$ & $6.7 \pm 0.7$ & $11.3 \pm 0.6$ \\
\hline Significance & N.S. & N.S. & P<0.001 & P<0.001 \\
\hline \multicolumn{5}{l}{} \\
\end{tabular}

\section{Fecundity on different food sources}

Total fecundity, pre-ovipositional period and adult longevity of the predatory mite on different food sources were compared using Kruskal-Wallis test. Although the predatory mite fed on all food sources oviposited, the numbers of eggs laid were significantly different with the different food sources (Table 2). A mean number of 31.1 eggs were deposited when fed on $A$. guerreronis. A much lesser number of eggs were laid when fed on other food sources (Table 2). When fed on $A$. guerreronis the shortest preoviposional period and longest adult longevity was obtained.

Table 2: Duration of pre-oviposition period, fecundity and longevity of $N$. baraki on different food sources

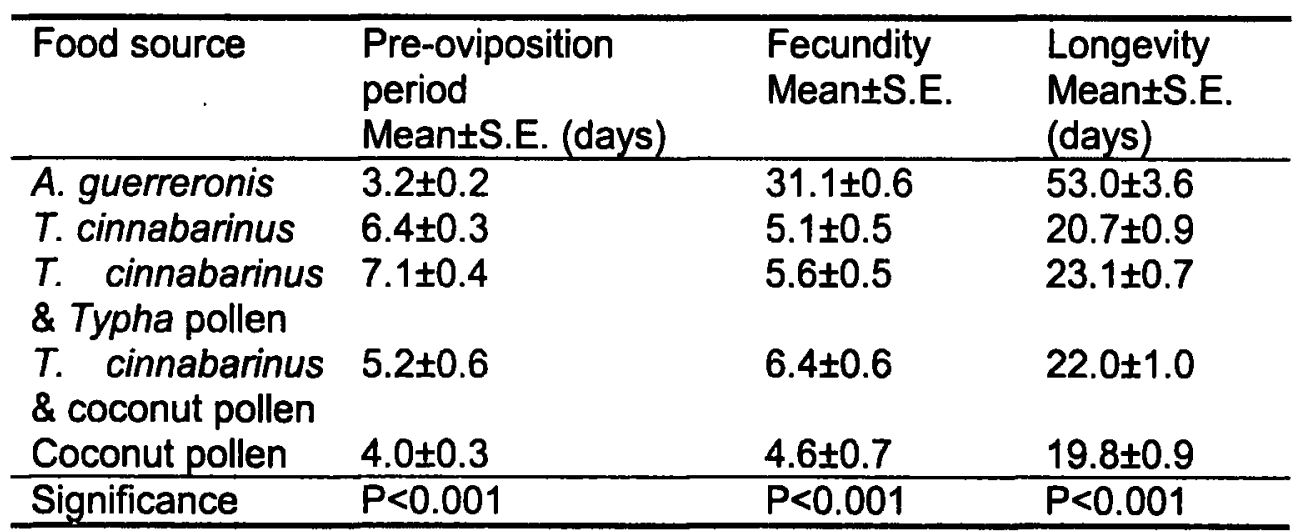




\section{Development and fecundity on T. putrescentiae}

$N$. baraki developed from egg to the adult in $11.1 \pm 0.1$ days (mean \pm S.E.) when fed on $T$. putrescentiae. Pre-oviposition period was $7.0 \pm 0.9$ days. The mean durations of larval, protonymphal and deutonymphal stages were $1.5 \pm 0.2,3.9 \pm 0.1$ and $4.0 \pm 0.2$ respectively. A mean number of $26.4 \pm 2.2$ eggs were deposited during its entire life of $70 \pm 1.8$ days. The fecundity of $N$. baraki when fed on $T$. putrescentiae was high although not as high as when fed on $A$. guerreronis. The oviposition patterns of the $N$. baraki on $A$. guerreronis and $T$. putrescentiae were different. N. baraki.deposited its full complement of eggs during the first 4 weeks of its adult life when fed on $A$. guerreronis while on $T$. putrescentiae the ovipositional period was spread over 10 weeks of its adult life (Figure.1).

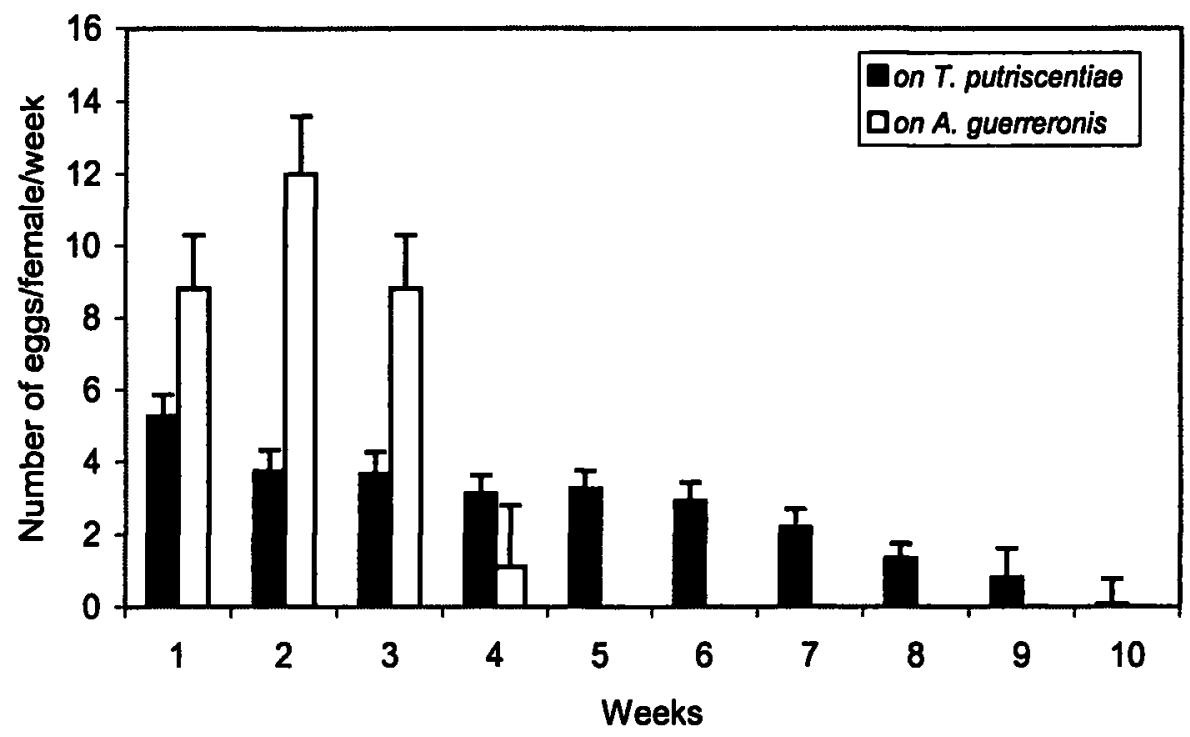

Figure 1: Total fecundity of $N$. baraki fed separately on T. putrescentiae and $A$. guerreronis recorded at weekly intervals

Determination of the development and fecundity of $T$. putrescentiae on Typha pollen and rice bran

T. putrescentiae developed and oviposited when fed on pollen and rice bran. Fecundity was high when fed on pollen $(163.5 \pm 23.4)$ than fed on rice bran (143.7 \pm 9.7$)$. On both food sources ovipostion continued until death of the mites. $T$. putrescentiae lived longer when fed on pollen ( $26.9 \pm 2.0$ days) than on rice bran (10.7 \pm 0.3 days). The daily oviposition on rice bran was higher than on pollen. The durations of immature stages on pollen and rice bran were $6.5 \pm 0.3$ and $6.9 \pm 0.2$ days respectively. 


\section{Determination of a suitable arena for mass breeding}

The increase in the number of predatory mites when reared on the three types of arenas at 21 days was compared using Kruskal-Wallis test. There was a significant difference $(P<0.01)$ among the three types of arenas. The highest mean number of predatory mites of $48.0 \pm 12.2$ was recorded in the closed arena without a water barrier. From the closed arena with water barrier and open arena with water barrier mean numbers of $31.0 \pm 6.5$ and $27.6 \pm 1.5$ predatory mites were recorded respectively. The weekly increase in the numbers of predatory mite is shown in Fig. 2. The highest number of predatory mites was obtained when reared on closed arena without a water barrier.

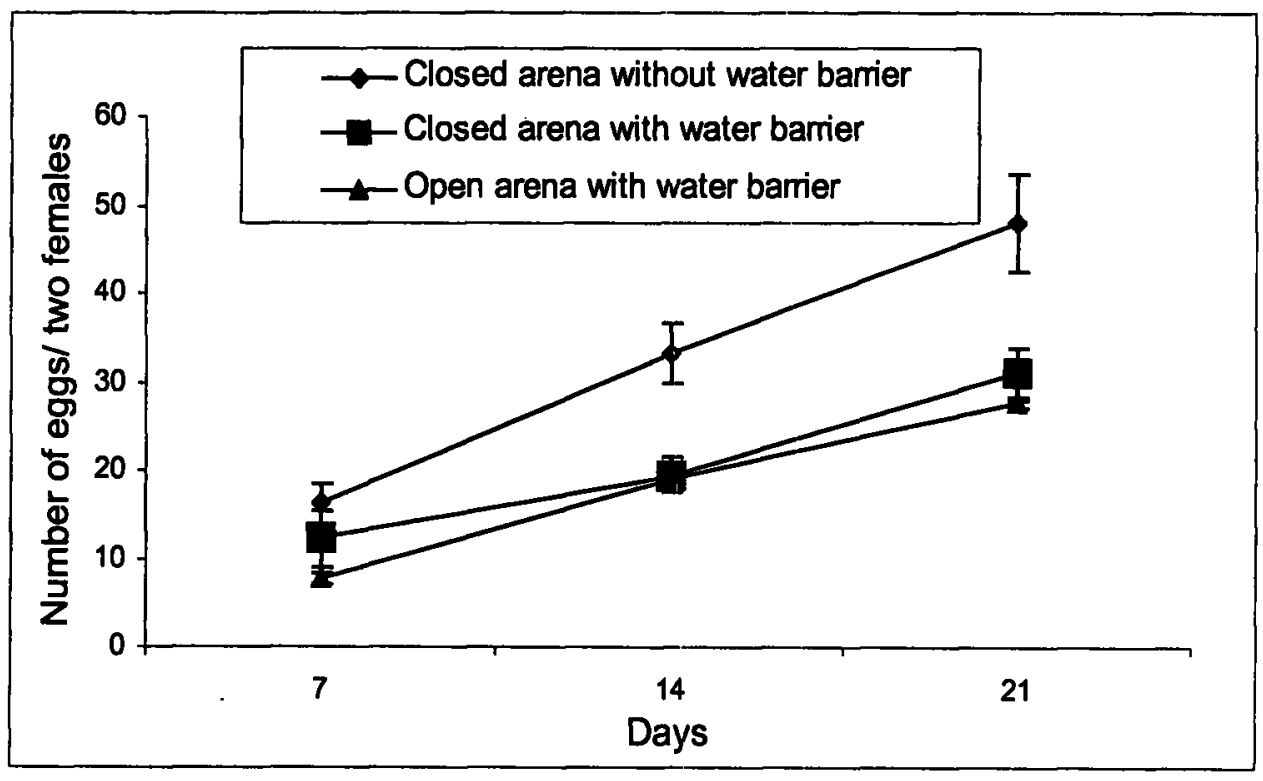

Figure 2: Population increase of $N$. baraki reared in three types of arenas over three weeks

\section{Mass rearing of N. baraki}

Two female predatory mites produced a mean number of $31.0 \pm 2.3$ motile stages and eggs in 3 weeks. 


\section{DISCUSSION}

A suitable laboratory prey for rearing of the predatory mite, N. baraki and a food source for rearing of its alternative prey, $T$. putrescentiae were determined. The predatory mite developed and reproduced satisfactorily on $T$. putrescentiae. None of the other food sources tested were suitable for mass rearing of the predatory mite due to low fecundity of $N$. baraki when fed on those food sources. The fecundity of the predatory mite fed on $T$. putrescentiae was only little less than that of its natural host, $A$. guerreronis. $T$. putrescentiae could be bred either on Typha pollen or rice bran but rice bran was more suitable because daily oviposition rate of $T$. putrescentiae was higher on rice bran than on pollen. Also, rice bran is a cheaper and easily available food source than Typha pollen. The predatory mite and its alternative prey could be successfully reared on the same arena. A closed arena without a water barrier, which is a modification of the basic arena developed by McMurtry and Scriven (1965) was found to be suitable for mass rearing. In this arena, a single female predatory mite produced a mean of 24 motile mites and eggs in 3 weeks. Pilot studies carried out in an insectary room revealed that the predatory mite could be successfully mass reared on $T$. putrescentiae and the latter on a mixture of rice bran in closed arenas.

The use of $T$. putrescentiae for mass rearing of $N$. baraki has several advantages. $T$. putrescentiae has not been reported to damage coconut. Therefore, it would be safe and easier to augment predatory mites in the field by introducing them with the rearing medium consisting of $T$. putrescentiae and rice bran. Also, mass rearing of $T$. putrescentiae is relatively easy as it could be readily bred on rice bran. Since $T$. putrescentiae is a scavenger it feeds on moulds and moulted skins of mites keeping the arena relatively clean. More importantly the arenas could be maintained with minimum intervention at least for one month. Therefore, the cost of production of the predatory mite would be low. From a commercial point of view this is highly advantageous. However, $T$. putrescentiae is a cosmopolitan species and therefore, could invade other arthropod and pathological cultures. This could be prevented by avoiding prolonged exposure of the arenas to handlers and the environment.

N. baraki could not be satisfactorily cultured in relatively open systems. They tend to escape from the arena and drown in the surrounding water barrier. This has been confirmed in the study too, which compared three different types of arenas. The closed arena without a water barrier yielded the highest number of mites in three weeks. However, it was observed that the lids of containers should be tightly fitted to avoid the predatory mite and the prey escaping from the arena. Lesser number of motile mites and eggs were produced under insectary conditions compared to more constant conditions in an incubator. 
N. baraki has been first described on Phararis sp. in Algeria (Athias-Henriot, 1966) and later reported from Thailand (Ehara and Bhandhufalck, 1977), Thaiwan (Tseng, 1983), India (Gupta, 1986) and China (Wu, 1986). The only record of it in association with $A$. guerreronis on coconut was from Puerto Rico (Howard et al., 1990). N. baraki is morphologically very similar to Neoseiulus mumai and Neoseiulus paspalivorus (Moraes, pers. comm.). In Sri Lanka, $N$. baraki was earlier referred to as $N$. aff. paspalivorus and subsequent studies of G.J de Moraes revealed that it is probably N. baraki.

Most of the phytoseiid mites that feed on eriophyoid pests are catergorized as Type III and IV species of predatory mites (Gerson et al., 2003). Type III species bear short mid-dorsal and lateral setae and are categorized as generalists that often prefer prey other than spider mites, readily consume pollen or plant exudates and. Type IV species consists only of species of Euseius that are generalists that appear to develop and reproduce best on pollen. Eriophyids constitute only part of their diverse diet (Gerson et al., 2003). According to the above categorization it seems that N. baraki is more like a Type III predatory species. Although under laboratory conditions it developed well on pollen it did not reproduce successfully on this food. This is known to be true for some type III predatory mites. Typhlodromalus manihoti (Moraes), which is used in the control of cassava green mite feeds on exudates of young cassava leaves or mildew but needs spider mites to reproduce (Bakker and Klein, 1992). Similarly, the fecundity of Typhlodromalus aripo (DeLeon), another acarine biological control agent increased when fed on cassava green mite (Gutierrez et al., 1999). However, fecundity of $N$. baraki did not increase when fed on the spider mite, $T$. cinnabarinus but increased when fed on the acarid mite, $T$. putrescentiae. Neoseiulus cucumeris a Type III species too breed well on the acarid mite Acarus siro L. (flour mite) and is used in mass breeding of the predatory mites for the control of thrips in glass houses (Ramakers \& van Lieburg, 1982).

The results of this study and previous observations revealed that $N$. baraki produced more progeny and developed more quickly when fed on $A$. guerreronis than on other prey. Some phytoseiids such as $T$. pyri and Euseius victoriensis showed the same trend when feed on eriophyoids. Gerson et al. (2003) stated that eriophyids could be the preferred or even the main prey of those phytoseiids, and not, as at times inferred, only an alternate diet. Examination of under storey plants in coconut mite infested fields failed to collect $N$. baraki, except from fruits of Borassus flabellifer and on Pisonia grandis (Moraes, pers. comm.). Further, N. baraki was not found on coconut flowers and was occasionally found on coconut leaves indicating that it may be confined to well protected sites (beneath the perianth) of the nuts. It has been postulated that although Type III phytoseiids do not seem to specialize on eriophyoids they may occur in specific sites in a manner similar to specialized phytoseiids (e.g. Phytoseiulus-Tetranychus 
association) (Gerson et al., 2003). It seems that the occurrence of a large number of $N$. baraki on coconut mite infested coconut is strongly influenced by the anatomy of the perianth of the nut they inhabit more than the presence of $A$. guerreronis. High relative humidity and lower temperatures in the microclimate beneath the perianth of nuts than in the surrounding environment and protection from predators that cannot creep under the perianth may have influenced the presence of $N$. baraki. Occupation of both $A$. guerreronis and $N$. baraki in the same habitat further suggest that $N$. baraki could be used as a biological control agent of coconut mite.

The major constraint in mass breeding of $N$. baraki using the method described in this study is that the insectary room and tools should be kept very clean and movement of personnel between breading rooms should be restricted to avoid contamination by undesired organisms. Invasion by a contaminant mite that feeds on the prey and the predatory mite prevented continuous rearing of $N$. baraki on several occasions. Therefore, studies are being continued to improve efficiency of rearing and to develop an arena that needs less maintenance, to determine optimum conditions for rearing of the predatory and prey mites and to streamline the production system.

\section{ACKNOWLEDGEMENTS}

We thank W.M.S. Wawegedara, A.D.N.T. Kumara, K.F.G. Perera and P.H.P.R. Silva and staff of the Crop Protection Division of the Coconut Research Institute for assisting in the study. We are grateful to Professor G.J. de Moraes of the University of Sao Paulo, Brazil for identifying the mites used in the study. We acknowledge the comments of Professor J. P. Edirisinghe on the manuscript. Financial assistance provided by the Ministry of Plantation Industries and Council of Agricultual Research Policy (CARP) is acknowledged.

\section{REFERENCES}

Aratchige, N.S. Herath, D.J. and Fernando, S. (2001). In Report of the Crop Protection Division. Annual Report of the Coconut Research Institute of Sri Lanka. p. 147.

Athias-Henriot, C. (1966). Contribution a l' etude des Amblyseius palearctiques (Acariens anactinotriches, Phytoseiidae). Bulletin Scientifique de Bourgogne, 24: 181-230.

Bakker, F.M. and Klein, M.E. (1992). Transtrophic interactions in cassava. Expt. Appl. Acarol. 14: 293-311. 
Cabrera R. I. C. (1995). Un 'medio a base de soya mas azucar para la var. thompsonii en medio liqido. 111 Encuentro Nac. Cient-Tec. De Bioplaguicidas. Expo-CREE. La Habana, Cuba. pp. 11-12.

Ehara, S. and Bhandhufalck, A. (1977). Phytoseiid mites of Thailand (Acarina: Mesotigmata). J. Fac. Edu. Tottori Univ., Nat. Sci., 27(2): 43-82.

Fernando, L.C.P. and Aratchige, N.S. (2003). Use of predatory mite Neoseiulus aff. paspalivorus in management of coconut mite (Aceria guerreronis). In Coconut eriophyid mite - Issues and strategies. Eds. H.P. Singh and P. Rethinam. pp. 43-49. Proceedings of the International workshop on coconut mite. Bangalore, India, 2003.

Fernando, L.C.P. Aratchig, N.S. and Peiris, T.S.G. (2003). Distribution patterns of coconut mite, Aceria guerreronis, and its predator Neoseiulus aff. paspalivorus in coconut palms. Expt. Appl. Acarol. 31, 71-78.

Fernando, L.C.P. Wickramanada, I.R. and Aratchige, N.S. (2002). Status of coconut mite, Aceria guerreronis in Sri Lanka. In Proceedings of the International workshop on coconut mite (Aceria guerreronis) 2000. Eds. Fernando, L.C.P., Moraes, G.J. de and Wickramananda, I.R., Coconut Research Institute, Sri Lanka, January 6-8.

Fernando, L.C.P. (1998). Annual Report of the Crop Protection Division, Coconut Research Institute, Sri Lanka.

Gerson, U. Smiley, R.L. and Ochoa, R. (2003). Mites (Acari) for pest control. Blackwell Science Ltd. pp.

Gupta, S.K. (1986). Fauna of India: Acari: Mesostigmata (Family: Phytoseiidae). Zoological Survey of India Calcutta, India.

Gutierrez, A.P. Yaninek, S. Neuenschwander, P and Ellis, C.K. (1999). A physiologically-based tritrophic metapopulation model of the African cassava food web. Proceedings, conference on numerical, statistical and information methods in crop and forest protection, Sassari, Italy, 19-22 may 1999.

Hall, R.A. and Espinosa, B. A. (1981). The coconut mite, Eriophyes guerreornis, with special reference to the problem in Mexico. Proc. 1981 British Crop Protection Conference - Pests and diseases, British Crop Protection Council, Farnham, U.K. pp. 113-120. 
Howard, F.W. Abreu-Rodríguez, E. and Denmark, H.A. (1990). Geographical and seasonal distribution of the coconut mite, Aceria guerreronis (Acari: Eriophyidae), in Puerto Rico and Florida, USA. J. Agric. Univ. Puerto Rico 74(3): 237-251.

Lampedro, L. and Luis Rosas, J. (1989). Selection of Hirsutella thompsonii Fisher strains to fight coconut mite Eriophyes guerreronis Keifer. 1. Pathogenecity experiments. Revista Mexicana de Micologia. 5, 225231.

Mariau, D. (1977). Aceria guerreronis: un important ravageur des cocoteraies africanes et américaines. Oléagineux. 32, 101-108.

Mariau, D. and Julia, J.F. (1970). L'acriose à Aceria guerreronis (Keifer), ravageur du cocotier. Oléagineux. 28, 133-135.

McMurtry, J.A. and Scriven, G.T. (1965). Insectary production of phytoseiid mites. J. econ. Ent. 58: 282-284.

Moore, D. and Alexander, L. (1987). Aspects of migration and colonization of the coconut palm by the coconut mite, Eriophyes guerreronis (Keifer) (Acari: Eriophyidae). Bull. Entomol. Res. 77, 641-650.

Moraes, G.J. de. Mcmurtry, J.A. and Denmark, H.A. (1986). A catalog of the mite family Phytoseiidae: References to taxonomy, synonymy, distribution and habitat. Brasilia: EMBRAPA-DDT. pp. 353.

Moraes, G.J. de and Zacarias, M.S. (2000). Use of predatory mites for the control of eriophyid mites. In Proceedings of the International workshop on coconut mite (Aceria guerreronis). Eds. L.C.P. Fernando, G. J. de Moraes and I. R. Wickramanada, pp 78-88. Coconut Research Institute workshop, Sri Lanka, January 6-8, 2000.

Rabindra, R.J. and Sreerama Kumar, P. (2003). Prospects of biological control of coconut mite. In Coconut eriophyid mite - Issues and strategies. Eds. H.P. Singh, and P.Rethinam. pp 35-42. Proceedings of the International workshop on coconut mite, Bangalore, India, 2003.

Ramakers, P.M.J. and Van Lieburg, M.J. (1982): Start of commercial production and introduction of Amblyseius mckenziei Sch. and Pr. (Acarina: Phytoseiidae) for the control of Thrips tabaci Lind. (Thysonoptera: Thripidae) in glasshouses. International Symposium on Crop Protection. 47(2): 541-545. 
Sathiamma, B. Radhakrishnan Nair, C.P. and Koshy, P.K. (1998). Outbreak of a nut infesting eriophyid mite Eriophyes guerreronis (K.) in coconut plantations in India. Indian Coconut Journal. 29(2), 1-3.

Tseng, Y.H. (1983). Further study on phytoseiid mites from Thaiwan (Acarina: Mesostigmata). Chin. J. Entomol. 3(1) 33-74.

Wu, W.N. (1986). [A new species and a new record of Amblyseius from Fujian (Chania) (Acarina: Phytoseiidae)] [in Chinese]. Wuyi Sci. J. 6:121-124.

Zuluaga, C.I. and Sanchez, P.A. (1971). La rona o esoriacion de los frutos del cocotero (Cocos nucifera L.) en Colombia. Oléagineux. 26, 767770 . 